\title{
PATIENT PREFERENCE FOR GENDERS OF HEALTH PROFESSIONALS
}

\author{
JAN J. KERSSENS,' JOZIEN M. BENSING' and MARGRIET G. ANDELA ${ }^{2}$
}

'The Netherlands Institute for Primary Health Care (NIVEL), P. O. Box 1568, 3500 BN, Utrecht, The Netherlands and ${ }^{2}$ Consumers Union, The Hague, The Netherlands

\begin{abstract}
Preferences for physicians' gender is an obvious and well documented example of considerations of patients' attitudes. But research carried out in this field is rather limited to the domain of family medicine. This article describes preferences for 13 different health professions: surgeons, neurologists, anaesthetists, internists, general practitioners, psychiatrists, psychologists, social workers, hospital and district nurses, home helps, gynaecologists and midwives. Our investigation also concerns the reasons for people's preferences. In February 1993 a self-administered survey was completed and returned by 961 out of 1113 (response $86 \%$ ) participants of the Dutch Health Care Consumers Panel, a panel resulting from a random sample of Dutch households. On a range of different health professions a varying minority of patients prefer a care provider of a particular gender. There are virtually no sex preferences for the more "instrumental" health professions (e.g. surgeons, anaesthetists). Gender preferences are stronger for those health professions more likely engaged in intimate and psychosocial health problems (e.g. gynaecologists and GPs). Preferences expressed do not relate to sex stereotypes of gender differences in instrumentality, expertise, efficiency, consultation length, and personal interest. The majority of persons who prefer female health professionals indicate that they talk more easily to females than to males, and feel more at ease during (internal) examination by females than by males. Persons who prefer male health professionals use the same reasons in favour of males. The discussion relates to gender differences in the communication style of male and female physicians. (C) 1997 Elsevier Science Ltd
\end{abstract}

Key words - patient preference, gender, health professions

\section{INTRODUCTION}

A fundamental assumption of the prevailing medical model is that medical care is based on objective scientific knowledge free from personal norms and values. The profession of medicine has gained enormously by adopting this biomedical model and in this respect its utility is beyond question (Odegaard, 1986). But a great change in society's attitudes to and expectations of the medical profession is underway (White, 1988). A clear manifestation of this change is the massive shift from a supply dominated health care model to a demand dominated model, e.g. in the "health for all" WHO program based on the perceived needs and preferences of individuals and populations served.

Preferences for physicians' gender is an obvious and well documented example considering patients' attitudes. Hopkins et al. (1967) were among the first to report that women patients preferred, when given a choice, to see a female GP in an urban group practice. Comparable group practice observations were made by Challacombe (1983) and Preston-Whyte et al. (1983). Kelly (1980) noted a clear correlation between physician's and patient's sex when Health Maintenance Organization members were allowed free choice in the selection of a family physician. Cook and Ronalds (1985a) affirmed this phenomenon in a large representative sample of general practitioners in the Manchester (U.K.) area. However, whether the results of all these studies can be generalized is doubtful, because the data were analysed without being corrected for the availability of female physicians (Cook and Ronalds, 1985b), which is the most important factor in choosing a GP (Gray, 1982). The most complete study so far of skewed sex distributions of physician/patients contacts has led Bensing et al. (1993) to conclude that:

female patients more often choose a female GP than do male patients if and when they have the opportunity to choose one; this tendency is stronger when there is more opportunity.

Patients' preferences for physicians' gender is also measured by means of surveys (Gray, 1982; Weisman and Teitelbaum, 1985). Female patients prefer female gynaecologists (Haar et al., 1975) and female physicians for women's health problems, especially for gynaecological procedures (Nichols, 1987). Graffy (1990) revealed that half of the female patients prefer to see a female doctor (for at least some problems), while the majority of men did not feel the doctor's sex mattered to them. In most studies of patients of both sexes some $25-45 \%$ of the patients-invariably more women than menreport gender preferences (McPherson and Small, 
1980; Fennema et al., 1990; Weyrauch et al., 1990). Women seem to prefer female physicians and men seem to prefer male physicians, so there is a similar gender preference (Ackerman-Ross and Sochat, 1980).

While there is a growing amount of literature to support the general idea that some people (mostly women) have declared a gender preference when visiting a health care provider, much less is known about the reasons for this preference. Shapiro suggests that there may be a general belief that male physicians are more competent, and female physicians more respectful and humane (Shapiro, 1979). In our society these traits are sex role stereotyped (Bem, 1981). This means that men are socialized to be technically competent, while women are socialized to be humane. This line of reasoning would imply that female patients prefer humaneness in health care professionals, while male patients prefer technical competence. However, Fennema et al. (1990) concluded that patients who prefer female physicians report humane behaviour as more characteristic of female physicians, while those who prefer male physicians report humane behaviour as more characteristic of men. Clearly, a more elaborate theoretical framework is necessary to explain gender preferences.

\section{RESEARCH QUESTIONS AND HYPOTHESES}

The documentation on patients' preferences for health professionals' gender is limited to the domain of family medicine with an emphasis on studies of female preferences. Our aim is to broaden this in two ways: not only women but also men are asked about their preferences, and these preferences are described not only for medical professionals but also for professionals in other parts of the health care system. A second research question refers to the reasons for patients' gender preferences; a hypothetical framework will be constructed to test patients' priorities in gender preferences in health care. In the last part of the paper the relationship of patients' gender preferences with the health professionals' labour market will be addressed. This research question follows from a general call in the literature for more female physicians, so that women will be in a position to choose a female physician (Hayden, 1991; Dillner, 1993). We determined whether this is indeed an important issue to patients.

This results in the following research questions:

(1) To what degree do female and male patients prefer female and male health care providers in four domains: medicine, mental health, nursing and obstetrics?

(2) What are the reasons for patients' gender preferences in health care?

(3) Is there potential demand for female health professionals in each of the traditionally male professions and for male professionals in each of the traditionally female professions?

This research was based on the general idea that there are (at least) three different types of reasons for preferring a physician of a particular sex that are sometimes strengthened, but sometimes neutralized, by their specific combinations. Different health care professions vary with regard to the characteristics that might constitute these gender preferences, which could explain the differences in direction and size of gender preferences. The first is the technical/ humane orientation of the different health care providers. For instance, in surgery, the emphasis is more on the technical side than in general practice. We expect a female gender preference for the more humane professions and a male gender preference for the more instrumental professions. The second characteristic has to do with the nature of the clinical procedures or intimacy of the topics that are discussed. For instance, hospital nurses encounter more situations of an intimate nature (e.g. undressing) than home helps; GPs are in general more inclined to discuss intimate problems as compared to anesthesists. We expect a same gender preference for the more intimate health professions and a neutral gender preference for the less intimate health professions. The third characteristic is the degree of female labour participation. Midwifery, for instance, is an almost exclusive female profession in the Netherlands, while gynaecology until now has had predominantly male care providers. We expect that gender preferences reflect the traditional division of labour in a country. These general hypotheses have been applied to 13 different health care professions, belonging to three domains of health care: medicine, mental health care, nursing, and obstetrics (Table 1). We have assumed that contradicting expectations in the various categories will result in a same gender preference (marked by a combination of $\mathrm{m}$ and $\mathrm{f}$ in the rightmost columns of Table 1).

The following hypotheses are formulated:

(1) overall male gender preferences will exist for surgeon, anesthesist and neurologist;

(2) overall female gender preferences will exist for social work, home help, district nurse and midwife; and

(3) same gender preferences will exist for internist, GP, psychiatrist, psychologist, hospital nurse and gynaecologist.

Apart from these general hypotheses we expect prior experience with a health provider of a certain sex to influence patients' gender preferences in health care. 
Table 1. Various combinations and corresponding hypotheses of gender preferences for 13 health care providers according to three fea-

\begin{tabular}{|c|c|c|c|c|c|}
\hline & $\begin{array}{c}\text { Humane (f) } \\
\text { Instrumental (m) }\end{array}$ & $\begin{array}{c}\text { Intimitate (s) } \\
\text { Less intimate (n) }\end{array}$ & $\begin{array}{l}\text { Traditional } \\
\text { Female/male }\end{array}$ & $\begin{array}{c}\text { Total } \\
\text { Female pat. }\end{array}$ & Male pat. \\
\hline Surgeon & $\mathrm{m}$ & $\mathbf{n}$ & m & m & m \\
\hline Neurologist & $\mathrm{m}$ & $\mathbf{n}$ & m & $\mathrm{m}$ & m \\
\hline Anaesthetist & m & $\mathbf{n}$ & m & $\mathrm{m}$ & $\mathrm{m}$ \\
\hline Internist & $\mathrm{m} / \mathrm{f}$ & s & $\mathrm{m}$ & $\mathrm{f}$ & $\mathrm{m}$ \\
\hline General practitioner & f & s & $\mathrm{m}$ & f & $\mathrm{m}$ \\
\hline Psychiatrist & $\mathrm{m} / \mathrm{f}$ & $\mathbf{s}$ & $\mathrm{m}$ & f & $\mathrm{m}$ \\
\hline Psychologist & f & $s$ & $\mathrm{~m} / \mathrm{f}$ & $f$ & $\mathrm{~m}$ \\
\hline Social worker & f & $s$ & $f$ & f & f \\
\hline Hospital nurse & $\mathrm{m} / \mathrm{f}$ & $s$ & f & $\mathrm{f}$ & m \\
\hline District nurse & f & $s$ & $f$ & $\mathrm{f}$ & $f$ \\
\hline Home help & f & $s$ & $f$ & f & i \\
\hline Gynaecologist & $\mathrm{m} / \mathrm{f}$ & s & m & f & m \\
\hline Midwife & f & $\mathbf{s}$ & f & f & $f$ \\
\hline
\end{tabular}

Notes: $\mathrm{m}=$ male preference; $\mathrm{f}=$ female preference; $\mathrm{s}=$ same gender preference; $\mathrm{n}=$ neutral preference.

Hypotheses:

1. Overall preferences for male providers: surgeon, neurologist, anaesthetist;

2. Overall preferences for female providers: social worker, district nurse, home help, midwife;

3. Same gender preference for: internist, GP, psychiatrist, psychologist, hospital nurse, gynaecologist.

\section{METHODS}

The respondents are participants of the Dutch Health Care Consumers Panel. This panel constitutes a random sample of Dutch households and is managed by the Consumers Union and The Netherlands Institute of Primary Health Care. In February 1993 a self-administered survey was completed and returned by 961 out of 1113 (response $86 \%$ participants. Respondents' gender is well balanced $(50 \%$ male and $50 \%$ female $)$. Respondents' age, gender, health insurance scheme and geographical location are representative of the Dutch population. Education and marital status deviate somewhat: single persons and persons with only primary education are somewhat under-represented. However, these two variables do not show any relation to preferences, reasons, or potential demand.

\section{Survey}

The questionnaire consisted of three parts. First, the preference for health professionals' gender in general was asked together with seven precoded reasons. This establishes a comparative base for the preferences for specific disciplines. The presentation of the seven reasons in conjunction with the health professional in general was meant to enable patients to elaborate the various reasons which focused on humaneness (three items), competence (three items) and nature of clinical procedures (one item). Second, a table was presented consisting of the 13 different care providers (surgeon, neurologist, anaesthetist, internist, general practitioner, psychiatrist, psychologist, social worker, hospital nurse, district nurse, home help, gynaecologist and midwife) in random order. Gender preferences were asked for each discipline and for each discipline the same seven reasons were presented. For instance, respondents indicated whether they talk more easily to a female GP, a male GP or if it makes no difference to them. The last part of the questionnaire dealt with medical consumption for each discipline in the last two years and whether a male or a female surgeon, neurologist, etc. was contacted.

\section{Analysis}

Most of the results are presented in tables with percentages. Sometimes the number of relevant cases dropped below 20 . In those instances percentages are not shown. Two concepts need some further explanation: the "same gender preference ratio" (SGP) and the "same gender opinion/preference" (SGOP) percentage.

The female (numerator) to male (denumerator) preference ratio in case of female respondents or the male to female ratio in case of male respondents is called the same gender preference (SGP) ratio. The statistical significance of this ratio is tested by means of a $\chi^{2}$ test statistic (or an exact binomial test when expected values are below 5) against the null hypothesis of an SGP ratio of one. An SGP ratio of one is obtained if, within the group of persons with a gender preference, the number of preferred male and female providers is equal. The various tables contain many statistical tests which increase the hazard of significance by chance. Therefore, alphas are adjusted by the Bonferroni procedure (an alpha of 0.05 divided by the number of tests). In Table 2, for instance, alpha is set at $0.05 / 13=0.0038$

The relevancy of the reasons is derived from the percentage of respondents with same gender opinions and preferences (SGOP) percentage. By this we mean the percentage of respondents who prefer a female internist and at the same time think (for instance) that female internists take more time then male ones do, or the percentage of respondents who prefer a male GP and at the same time indicate that (for instance) they talk more easily to male GPs than to female GPs. Again, a $\chi^{2}$ statistic (or 
Table 2. Percentage of women respondents according to their gender preferences for 13 health care providers $(n=483)$

\begin{tabular}{|c|c|c|c|c|}
\hline$\therefore$ & No preference & Preference for males & - Preference for females & $\begin{array}{l}\text { Same gender }{ }^{b} \text { preference } \\
\text { (SGP) ratio }\end{array}$ \\
\hline $\begin{array}{l}\text { Surgeon } \\
\text { Neurologist } \\
\text { Anaesthetist } \\
\text { Internist } \\
\text { General practitioner } \\
\text { Psychiatrist } \\
\text { Psychologist } \\
\text { Social worker } \\
\text { Hospital nurse } \\
\text { District nurse } \\
\text { Home help } \\
\text { Gynaecologist } \\
\text { Midwife }\end{array}$ & $\begin{array}{l}87.8 \\
91.9 \\
92.3 \\
84.9 \\
71.8 \\
81.2 \\
78.5 \\
73.3 \\
53.4 \\
64.4 \\
60.0 \\
52.8 \\
53.4\end{array}$ & $\begin{array}{l}7.5 \\
2.5 \\
4.1 \\
4.6 \\
8.5 \\
3.9 \\
3.1 \\
2.5 \\
1.7 \\
0.2 \\
0.6 \\
5.0 \\
1.7\end{array}$ & $\begin{array}{r}4.8 \\
5.6 \\
3.5 \\
10.6 \\
19.7 \\
14.9 \\
18.4 \\
24.2 \\
44.9 \\
35.4 \\
39.3 \\
42.2 \\
44.9\end{array}$ & $\begin{array}{c}0.64 \\
2.25 \\
0.85 \\
2.30^{\mathrm{a}} \\
2.32^{\mathrm{a}} \\
3.79^{\mathrm{a}} \\
5.93^{\mathrm{a}} \\
9.75^{\mathrm{a}} \\
10.9^{\mathrm{a}} \\
171^{\mathrm{a}} \\
63.3^{\mathrm{a}} \\
8.5^{\mathrm{a}} \\
27.1^{\mathrm{a}}\end{array}$ \\
\hline
\end{tabular}

${ }^{4} P<0.0038$;

bemale to male preference ratio..

an exact binomial test when expected values are below 5) is used to test SGOP for statistical significance. In this case the null hypothesis is the situation where the number of persons with an SGOP is equal to the number of persons with an "opposite gender opinion/preference" (OGOP). Table 4 presents SGOP percentages besides OGOP percentages and the percentage of persons with a neutral gender preference (NGOP). In Tables 5 and 6 only SGOP percentages are shown. Note that the statistical significance of these cell entries do not necessarily correspond with the size of the percentage. For example, an SGOP of $30 \%$ can be significant (for instance, when OGOP is $1 \%$ and NGOP is $69 \%$ ) as well as not significant (for instance, when OGOP is $30 \%$ and NGOP is $40 \%$ ). Those SGOPs of $50 \%$ and higher are always greater than the sum of the corresponding OGOPs and NGOPs. Therefore, in the text only SGOPs of over $50 \%$ will be mentioned.

\section{Multiple logistic regression}

In order to examine the simultaneous association between different background variables and the chance of preferring a professional of a particular gender, various multiple logistic regression analyses were performed. This was done only for GPs, as this was the only health care profession in which both gender preferences were found, combined with enough numbers of patients with prior experience with providers of both sexes. The analysis is performed in two stages. In the first stage the dependent variable is whether or not people have gender preferences, and in the second stage the dependent variable is whether the preferred professional is female or male. The second stage relates to respondents with a preference only. In both stages the following independent variables are introduced:

(1) gender (female $=1$ );

(2) age (centred around the mean age of 45);

(3) marital status (married = 1);

(4) education (centred around the mean education of five years of secondary school); and
(5) prior contact with a female general practitioner (prior contact $=1$ ).

\section{RESULTS}

\section{Preferences}

The preference data are presented separately for female and male respondents. This section starts with the women.

Except for the general practitioner and the gynaecologist, the disciplines in the field of medicine are marked by a relatively small amount of women with gender preferences (Table 2). The general practitioners' gender is subject to preference by $28 \%$ of the female respondents and the majority of them prefer female GPs over males. About the same applies to internists. Women do not often seem to have preferences for the gender of surgeons, neurologists or anaesthetists, and when they do, there are not in favour of a particular gender.

The mental health care providers show a clear ordinal ranking of psychiatrist, psychologists and social workers. Successive preference percentages are: $19 \%, 22 \%$ and $27 \%$. The SGP ratios are (rounded) 4 for the psychiatrist, 6 for the psychologist and $\mathbf{1 0}$ for the social worker. Within the field of mental health there are slightly more preferences than in the field of somatic medicine, and the preferences shift more towards female care providers.

According to the female respondents, gender preferences are predominant in the fields of nursing and obstetrics. About $35-45 \%$ of the women prefer a care provider of the female gender. Preferences for male professionals are virtually absent, leading to very high SGPs (ranging from 9 to well over 100 ).

Male respondents (Table 3) differ from women in various respects. Men show less gender preferences over a range of disciplines. Only in the field of medicine and in the case of home help do men show preferences in a similar pattern. Men (with a preference) definitely prefer male surgeons (SGP 28) and male neurologists (SGP 10). In the field of 
Table 3. Percentage of male respondents according to their gender preferences for 13 health care providers $(n=478)$

\begin{tabular}{|c|c|c|c|c|}
\hline & No preference & Preference for males & Preference for females & $\begin{array}{l}\text { Same gender'preference } \\
\text { (SOP) ratio }\end{array}$ \\
\hline $\begin{array}{l}\text { Surgeon } \\
\text { Neurologist } \\
\text { Anaesthetist } \\
\text { Internist } \\
\text { General practitioner } \\
\text { Psychiatrist } \\
\text { Psychologist } \\
\text { Social worker } \\
\text { Hospital nurse } \\
\text { District nurse } \\
\text { Home help } \\
\text { Gynaecologist } \\
\text { Midwife }\end{array}$ & $\begin{array}{l}82.0 \\
90.8 \\
95.4 \\
85.4 \\
81.8 \\
91.4 \\
88.3 \\
83.1 \\
81.6 \\
73.4 \\
65.7 \\
87.0 \\
81.6\end{array}$ & $\begin{array}{r}17.4 \\
8.4 \\
3.8 \\
13.2 \\
16.3 \\
5.9 \\
7.9 \\
3.6 \\
0.4 \\
1.0 \\
0.4 \\
4.2 \\
0.4\end{array}$ & $\begin{array}{r}0.6 \\
0.8 \\
0.8 \\
1.5 \\
1.9 \\
2.7 \\
3.8 \\
13.4 \\
18.0 \\
25.5 \\
33.9 \\
8.8 \\
18.0\end{array}$ & $\begin{array}{l}27.7^{\mathrm{a}} \\
10.0^{\mathrm{a}} \\
4.50^{\mathrm{a}} \\
9.00^{\mathrm{u}} \\
8.67^{\mathrm{a}} \\
2.15 \\
2.11 \\
0.27^{\mathrm{a}} \\
0.11^{\mathrm{a}} \\
0.04^{\mathrm{a}} \\
0.01^{\mathrm{a}} \\
0.48 \\
0.02^{\mathrm{a}}\end{array}$ \\
\hline
\end{tabular}

${ }^{4} P<0.0038$

'Male to female preference ratio..

medicine they always prefer a male. Male preferences for psychiatrists and psychologists are equally spread over the two sexes. Men do not prefer male professionals as regards social work, the entire field of nursing, and obstetrics. On the contrary, in these disciplines, they prefer care providers of the opposite sex. Because of this opposite gender preference the SGPs drop to almost 0 .

\section{Reasons}

We inquired about the reasons for gender preferences separately among those who prefer a female health professional in general and those who prefer a male. The respondents' own sex in connection with their opinion is, for the time being, assumed to be less important. The results are, therefore, presented irrespective of respondents' sex (Table 4).

The majority of persons who prefer a female health professional have indicated that they talk more easily to a female than to a male health professional. The same gender opinion/preference (SGOP) percentage for this reason is $77 \%$. An even greater majority of respondents who prefer a female health professional have reported that they feel more at ease during (internal) examination by a female than by a male (SGOP $83 \%$ ). These two reasons make the greatest difference. Two of the reasons are of some interest: some of the people who prefer a woman believe that she takes a more personal interest in her patients than a male professional does (SGOP 45\%) and that she takes more time with her patients $(24 \%)$. According to the other SGOP percentages, three of the seven reasons hardly apply. People who prefer a female do not think that a female health professional is more instrumental, has more expertise, or that she treats her patients more efficiently than a male professional does.

The table also shows the reasons of respondents who prefer a male health professional in general. The results are similar to the above in the sense that persons with a preference for men feel more at ease and find it easier to talk with a male health professional than with a female (SGOP $70 \%$ and $67 \%$, respectively). When we compare persons with a preference for a female health professional with those who prefer a male, it is obvious that the former have somewhat stronger feelings than the latter.

Table 4. Percentage of respondents who prefer a female health professional in general $(n=127)$ and respondents who prefer a male health professional in general $(n=57)$ according to their opinon on seven reasons for gender preferences

\begin{tabular}{|c|c|c|c|c|c|c|c|}
\hline & $\begin{array}{l}\text { I talk more } \\
\text { easily to a... }\end{array}$ & $\begin{array}{l}\text { A....is more } \\
\text { instrumental }\end{array}$ & $\begin{array}{l}\text { A...takes a more personal } \\
\text { interest in me }\end{array}$ & $\begin{array}{l}\text { With a...I feel } \\
\text { more at ease } \\
\text { when } \\
\text { intimately/ } \\
\text { physically } \\
\text { examined }\end{array}$ & $\begin{array}{c}\text { A...has more } \\
\text { expertise }\end{array}$ & $\begin{array}{l}\text { A...takes more } \\
\text { time for me }\end{array}$ & $\begin{array}{l}\text { A...treats more } \\
\text { efficiently }\end{array}$ \\
\hline \multicolumn{8}{|c|}{ Persons with female preferences } \\
\hline Female & $77.2^{\mathrm{ub}}$ & $9.4^{b}$ & $44.9^{\mathrm{ab}}$ & $82.7^{\mathrm{ub}}$ & $3.9^{b}$ & $23.6^{\mathrm{ab}}$ & $15.7^{\mathrm{ab}}$ \\
\hline Male & 2.4 & 25.2 & 0.0 & 3.9 & 0.0 & 0.0 & 0.8 \\
\hline No difference & 20.5 & 65.4 & 55.1 & 13.4 & 96.1 & 76.4 & 83.5 \\
\hline \multicolumn{8}{|c|}{ Persons with male preferences } \\
\hline \multirow{3}{*}{$\begin{array}{l}\text { Female } \\
\text { professional } \\
\text { Male } \\
\text { professional } \\
\text { No difference }\end{array}$} & 7.0 & 11.1 & 7.3 & 8.8 & 0.0 & 7.3 & 1.8 \\
\hline & $70.2^{u b}$ & $35.2^{b}$ & $23.6^{b}$ & $66.7^{\mathrm{ub}}$ & $9.1^{b}$ & $9.1^{b}$ & $8.9^{b}$ \\
\hline & 22.8 & 53.7 & 69.1 & 24.6 & 90.9 & 83.6 & 89.3 \\
\hline
\end{tabular}

"P $<0.0035$ :

'Same gender opinion/preference (SGOP) percentage. 
Thus far it was assumed that in connection with their opinion the respondents' own sex is of less importance than their gender preference. This assumption is confirmed by the reason of "feeling more at ease". A log-linear analysis of the three way contingency table (respondents' sex, gender preference and opinion) shows that the interaction of gender preference and opinion explains about five times more variation in the data than the interaction between sex and opinion (data not in table).

The above results apply to health professionals in general, but an analysis of the precoded reasons for each of the 13 disciplines leads to a generalization of the earlier results. The same two reasons make the greatest difference.

Table 5 shows the percentages of respondents who prefer female care providers and who are, at the same time, of the opinion that female care providers are easier to talk to, more instrumental, etc., than males. Table 5 thus shows same gender opinion/preference (SGOP) percentages (not opposite gender opinion/preference or indifference percentages). With regard to the first reason-talking more easily to a female-all care providers receive significant SGOPs. The range is from $70 \%$ in the case of the female district nurse to $97 \%$ in the case of the female psychologist. The third reason-a female takes a more personal interest-seems to apply to some female care providers but not for others. Substantial SGOPs $(56-61 \%)$ are only obtained for female neurologists, anaesthetists, social workers and home helps. Persons with a preference for female care providers-the fourth reason-generally indicate that they feel more at ease during (internal) examinations with a woman. The SGOPs range from $52 \%$ in case of female home helps to $95 \%$ in case of female anaesthetists.
Female internists, female GPs and female gynaecologists also obtain high SGOPs.

For persons who prefer male care providers the first reason-talking more easily to a male-also seems very important (Table 6). SGOPs of $50 \%$ or higher are calculated for all the care providers presented, ranging from $53 \%$ for male anaesthetists to $96 \%$ for male social workers. The second reason-a male is more instrumental-is relevant only in connection with preferences for male surgeons, neurologists and anaesthetists. For the fourth reasonfeeling more at ease during (internal) examinations-substantial SGOPs are calculated only for male internists, GPs and hospital nurses. The other reasons do not seem to apply as regards preferences for male care providers.

\section{Potential demand}

The extent of patient preferences for female GPs, in relation to the gender of their own GP, is an indication of the potential demand for female GPs. The same goes for all the other disciplines. Table 7 shows various results with regard to potential demand. The leftmost column of percentages contains information about the sex distribution of the 13 care providers in Dutch health care.

We asked whether the respondents had visited (at least once) a surgeon, neurologist, etc. in the past two years. The GP is the most frequently visited health professional. More than $\mathbf{9 0 \%}$ of the respondents visited their GP at least once in the last two years. Consumption of other services is much lower, of course. Somewhere in the middle the district nurse is found $(16 \%)$ and the least contacted is the psychiatrist: only $3 \%$ in the last two years.

The respondents also reported whether they had visited a female surgeon, neurologist, etc., a male surgeon, neurologist etc., or both (in case of more

Table 5. Percentage of respondents with same gender opinions/preferences for female health care providers on seven reasons for 13 disciplines

\begin{tabular}{|c|c|c|c|c|c|c|c|c|}
\hline & Reason $1(\%)$ & Reason $2(\%)$ & Reason $3(\%)$ & Reason $4(\%)$ & Reason $5(\%)$ & Reason $6(\%)$ & Reason $7(\%)$ & $n$ \\
\hline Surgeon & $84.6^{a}$ & 8.0 & 45.8 & $80.0^{n}$ & 8.3 & 33.3 & 20.8 & 26 \\
\hline Neurologist & $96.7^{\mathrm{a}}$ & 6.9 & $60.0^{\circ}$ & $83.3^{\mathrm{a}}$ & 3.6 & 33.3 & 14.3 & 31 \\
\hline Anaesthetist & $95.0^{\mathrm{a}}$ & 5.3 & $52.6^{\mathrm{B}}$ & $95.0^{\mathrm{a}}$ & 10.5 & 36.8 & 5.3 & 21 \\
\hline Internist & $81.0^{\mathrm{a}}$ & 7.4 & $34.5^{a}$ & $91.2^{\mathrm{n}}$ & 3.6 & $24.1^{\mathrm{a}}$ & 9.3 & 58 \\
\hline $\begin{array}{l}\text { General } \\
\text { practitioner }\end{array}$ & $84.5^{\mathrm{a}}$ & 5.2 & $42.4^{\mathrm{a}}$ & $87.4^{\mathrm{u}}$ & 6.2 & $22.7^{\mathrm{a}}$ & $14.6^{\mathrm{a}}$ & 104 \\
\hline Psychiatrist & $95.2^{a}$ & 7.8 & $45.6^{\mathrm{n}}$ & $70.1^{\mathrm{u}}$ & $9.3^{\mathrm{a}}$ & $23.4^{a}$ & $14.7^{\mathrm{x}}$ & 85 \\
\hline Psychologist & $97.2^{\mathrm{a}}$ & 6.1 & $47.0^{\mathrm{a}}$ & $67.7^{4}$ & 11.3 & $25.5^{\mathrm{a}}$ & 12.4 & 107 \\
\hline Social worker & $88.8^{a}$ & 13.8 & $61.2^{\mathrm{n}}$ & $54.8^{a}$ & $17.1^{\mathrm{a}}$ & $38.0^{\text {t }}$ & $23.3^{\sharp}$ & 181 \\
\hline Hospital nurse & $68.8^{\mathrm{u}}$ & 16.2 & $43.4^{\mathrm{u}}$ & $80.9^{\mathrm{a}}$ & $20.1^{a}$ & $35.0^{a}$ & $26.1^{\mathrm{a}}$ & 204 \\
\hline District nurse & $70.0^{\mathrm{a}}$ & 15.4 & $46.7^{\mathrm{B}}$ & $65.4^{\mathrm{a}}$ & $30.5^{\mathrm{a}}$ & $35.3^{n}$ & $25.8^{\mathrm{A}}$ & 293 \\
\hline Home help & $71.7^{\mathrm{A}}$ & $33.4^{\mathrm{a}}$ & $55.6^{n}$ & $52.1^{2}$ & $63.4^{\mathrm{at}}$ & $47.7^{\mathrm{a}}$ & $54.6^{2}$ & 352 \\
\hline Gynaecologist & $78.2^{\mathrm{a}}$ & 10.6 & $42.5^{\mathrm{a}}$ & $91.5^{\mathrm{a}}$ & $21.0^{\mathrm{a}}$ & $27.6^{\mathrm{a}}$ & $17.5^{\mathrm{a}}$ & 246 \\
\hline Midwife & $76.6^{a}$ & 13.0 & $46.7^{n}$ & $81.6^{4}$ & $30.6^{a}$ & $29.0^{\mathrm{a}}$ & $22.4^{\mathrm{a}}$ & 303 \\
\hline
\end{tabular}

$P<0.00055$

Reason 1: I talk more easily to a female...

Reason 2: A female...is more instrumentai

Reason 3: A female...takes a more personal interest in me

Reason 4: With a female...I feel more at ease when intimately/physically examined

Reason 5: A female...has more expertise

Reason 6: A female...takes more time for me

Reason 7: A female...treats more efficiently. 
Table 6. Percentage of respondents with same gender opinions/preferences for male health care providers on seven reasons for nine disciplines $^{\mathrm{b}}$

\begin{tabular}{|c|c|c|c|c|c|c|c|c|}
\hline & Reason $1(\%)$ & Reason $2(\%)$ & Reason $3(\%)$ & Reason $4(\%)$ & Reason $5(\%)$ & Reason $6(\%)$ & Reason $7(\%)$ & $\bar{n}$ \\
\hline Surgeon & $53.7^{\star 4}$ & $50.9^{4}$ & 16.2 & $44.2^{\mathrm{a}}$ & $30.5^{\mathrm{a}}$ & 10.8 & $28.8^{\mathrm{n}}$ & 119 \\
\hline Neurologist & $68.1^{\text {म }}$ & $52.1^{\mathrm{u}}$ & 26.1 & $59.6^{2}$ & 25.5 & 17.8 & 17.4 & 52 \\
\hline Anaesthetist & 52.9 & $51.4^{\mathrm{a}}$ & 23.5 & 40.0 & 28.6 & 9.1 & 26.5 & 38 \\
\hline Internist & $72.7^{\mathrm{y}}$ & $48.1^{\mathrm{z}}$ & 22.1 & $64.1^{\mathrm{a}}$ & 14.3 & 11.8 & 15.4 & 85 \\
\hline $\begin{array}{l}\text { General } \\
\text { practitioner }\end{array}$ & $77.5^{\mathrm{a}}$ & $42.3^{\mathrm{a}}$ & $30.9^{a}$ & $64.5^{\mathrm{a}}$ & $13.0^{\mathrm{a}}$ & $22.0^{\mathrm{a}}$ & 17.3 & 119 \\
\hline Psychiatrist & $72.7^{\mathrm{a}}$ & $39.5^{\mathrm{a}}$ & 28.6 & 28.2 & 25.6 & $21.4^{\mathrm{a}}$ & 21.4 & 47 \\
\hline Psychologist & $79.6^{\mathrm{a}}$ & $39.6^{\mathrm{a}}$ & 41.7 & 31.9 & 20.8 & 20.8 & 27.1 & 53 \\
\hline Social worker & $96.0^{\mathrm{at}}$ & $45.8^{\mathrm{a}}$ & 26.9 & 45.0 & 12.5 & 25.0 & 20.8 & 29 \\
\hline Hospital nurse & $80.0^{\mathrm{a}}$ & 25.0 & 40.0 & 50.0 & 25.0 & 40.0 & 25.0 & 20 \\
\hline
\end{tabular}

${ }^{2} P<0.00079$;

bOnly nine disciplines because the number of respondents with preference for a male district nurse, a male home help, a male gynaecologist and a male midwife dropped below 20;

Reason 1: I talk more easily to a male...

Reason 2: A male...is more instrumental

Reason 3: A male...takes a more personal interest in me

Reason 4: With a male...I feel more at ease when intimately/physically examined

Reason 5: A male...has more expertise

Reason 6: A male...takes more time for me

Reason 7: A male...treats more efficiently.

visits). If for a substantial number of respondents the gender of the visited health professional is not in accordance with the preferred gender, there is a potential demand for a health professional of a particular gender. In this way a conservative estimate of the potential demand has been obtained.

The number of respondents is a function of the varying consumption of services and gender preferences (absolute numbers in Table 7). Some combinations are encountered very rarely (e.g. female surgeons). The potential demand for female GPs and gynaecologists is quite clear. A substantial number of patients who prefer female GPs have been visiting men only. With respect to gynaecologists, this is even more marked. Finally, there seems to be some potential demand for female psychologists. Potential demand for male care providers is virtually absent.

\section{Other predictors of gender preferences}

In the previous results we have already focused on patients' own gender as a predictor for gender preferences in health care. In this last section multiple logistic regression analysis is applied to account for other predictors as well (only for GP gender preferences). Table 8 shows the main results, odd ratios calculated from the logistic equation of two seperate stages.

The leftmost column refers to gender preferences for general practitioners. Compared to males, females have more gender preferences for GPs. Age and marital status as well as education are of little importance because the associated odd ratios do not reach statistical significance. Prior contact with a female GP is most strongly connected with gender preferences for GPs. Respondents who have seen a female GP in the last two years have an odds almost three times higher than the odds of those having seen a male GP only.
Within the group of respondents with a GP gender preference, the same variables show a significant relation to the choice of a female GP (see the odd ratios in the second column of Table 8). Female respondents and those with prior contact with a female GP are strongly in favour of female GPs. Age is also significant, with younger persons having stronger preferences for female GPs than older people. Marital status and education are of no concern.

\section{DISCUSSION}

On a range of different health professions a varying minority of patients prefer a care provider of a particular gender. Gender preferences are stronger among female patients than among male patients, and more explicit for the domains of nursing and obstetrics than for the domains of medicine and mental health care. Taken together these results mean that about $35-45 \%$ of female patients prefer a care provider of the female gender in the fields of nursing and obstetrics. Our hypotheses about the pattern of gender preferences are partly confirmed, and partly refuted. Our hypothesis that the typical instrumental health care professions like surgeons, neurologists, and anaesthetists would show overall male gender preferences could not be confirmed in our data. Indeed, there are virtually no sex preferences $(<15 \%)$ for the typical "instrumental" professions, not any among female patients, and, surprisingly, hardly any among male patients. A possible explanation for this unexpected result was shown in the analysis of the reasons that patients give for their preferences: these do not seem to relate to sex stereotypes of gender differences in instrumentality, expertise, or efficiency. These variables have proven to be of little importance in gender preferences. This may also explain the overall 
lower gender preference among male patients as compared to female patients.

In our data we did find corroboration for the second hypothesis that predicted overall female gender differences for social workers, district nurses and midwives. Male as well as female patients expressed significant preferences for female health care providers in this group. This means that the combination of humane-oriented professions with traditional female labour participation has a stronger influence on patients' gender preferences than the nature of clinical procedures or type of topics discussed that, taken alone, would predict a same gender preference in these professions. Same gender preferences were predicted in those professions that involve clinical interventions of an intimate nature, in which either the profession is partly humane, partly instrumental-oriented, or in which the type of profession (humane vs instrumental) and the traditional labour division between men and women would lead to contradicting expectations (hypothesis 3). Here we see an interesting picture emerge. For female patients the results are completely in line with our expectations. However, for male patients they are not. For male patients the traditional labour division between male and female providers is the best predictor for patients' gender preferences.

These results can be considered as a refinement towards the results of previous studies in this field. Earlier studies of GP gender preferences have pointed out the similarity between the patients' and the physicians' sex (Kelly, 1980; Ackerman-Ross and Sochat, 1980; Blake, 1990). Our study has confirmed this and furthermore demonstrated that same gender preferences also hold for internists, neurologists, but not for surgeons and anaesthetists. This is probably due to the fact that the clinical procedures of general medicine do more often involve a higher degree of intimacy than surgical procedures. The physician's gender is particulary salient under conditions in which examination require complete disrobing, extensive body probing or examination of the genitalia (Kitzinger, 1990; Heaton and Marquez, 1990). This is also why the gynaecologist's gender is important to half of the

Table 7. Percentages of male providers, percentages of patients with one or more contacts in the last two years, absolute number of patients with a gender preference and one or more contacts in the last two years $(n=961)$, and percentages of patients where gender preferences are in accordance with the sex of the contacted care provider

\begin{tabular}{|c|c|c|c|c|}
\hline & $\%$ Male providers & $\begin{array}{l}\% \text { Patients with contact } \\
\text { in last two years }\end{array}$ & $\begin{array}{l}\text { Number of patients } \\
\text { with preference and } \\
\text { contact(s) }\end{array}$ & $\begin{array}{l}\text { Gender preference in } \\
\text { accordance with contact(s) }\end{array}$ \\
\hline $\begin{array}{c}\text { Surgeon } \\
\text { male } \\
\text { female }\end{array}$ & $96.9 \%$ & $26.1 \%$ & $\begin{array}{r}44 \\
7\end{array}$ & $\begin{array}{c}95.5 \% \\
-\end{array}$ \\
\hline $\begin{array}{l}\text { Neurologist } \\
\text { male } \\
\text { female }\end{array}$ & $83.6 \%$ & $9.3 \%$ & $\begin{array}{r}10 \\
3\end{array}$ & - \\
\hline $\begin{array}{l}\text { Anaesthetist } \\
\text { male } \\
\text { female }\end{array}$ & $77.1 \%$ & $16.5 \%$ & $\begin{array}{l}9 \\
5\end{array}$ & - \\
\hline $\begin{array}{l}\text { Internist } \\
\text { male } \\
\text { female }\end{array}$ & $82.8 \%$ & $18.1 \%$ & $\begin{array}{l}28 \\
13\end{array}$ & $100.0 \%$ \\
\hline $\begin{array}{l}\text { General practitioner } \\
\text { male } \\
\text { female }\end{array}$ & $86.8 \%$ & $91.3 \%$ & $\begin{array}{r}116 \\
97\end{array}$ & $\begin{array}{l}98.3 \% \\
50.5 \%\end{array}$ \\
\hline $\begin{array}{l}\text { Psychiatrist } \\
\text { male } \\
\text { female }\end{array}$ & $73.8 \%$ & $2.8 \%$ & $\begin{array}{l}3 \\
5\end{array}$ & - \\
\hline $\begin{array}{l}\text { Psychologist } \\
\text { male } \\
\text { female }\end{array}$ & $52.0 \%$ & $6.5 \%$ & $\begin{array}{r}3 \\
23\end{array}$ & $\overline{69.6 \%}$ \\
\hline $\begin{array}{l}\text { Social worker } \\
\text { male } \\
\text { female }\end{array}$ & $36.1 \%$ & $11.0 \%$ & $\begin{array}{r}5 \\
31\end{array}$ & $-\overline{87.1} \%$ \\
\hline $\begin{array}{l}\text { Hospital nurse } \\
\text { male } \\
\text { female }\end{array}$ & $27.6 \%$ & $31.9 \%$ & $\begin{array}{r}7 \\
71\end{array}$ & $\overline{95.8} \%$ \\
\hline $\begin{array}{l}\text { District nurse } \\
\text { male } \\
\text { female }\end{array}$ & $4.9 \%$ & $14.4 \%$ & $\begin{array}{r}3 \\
54\end{array}$ & $\overline{98.1 \%}$ \\
\hline $\begin{array}{l}\text { Home help } \\
\text { male } \\
\text { female }\end{array}$ & $0.5 \%$ & $7.6 \%$ & $\begin{array}{r}1 \\
35\end{array}$ & $100.0 \%$ \\
\hline $\begin{array}{l}\text { Gynaecologist } \\
\text { male } \\
\text { female }\end{array}$ & $86.4 \%$ & $16.9 \%$ & $\begin{array}{l}11 \\
48\end{array}$ & $27.1 \%$ \\
\hline $\begin{array}{l}\text { Midwife } \\
\text { male } \\
\text { female }\end{array}$ & $3.3 \%$ & $9.2 \%$ & $\begin{array}{r}2 \\
40\end{array}$ & $100.0 \%$ \\
\hline
\end{tabular}

"Various sources, available on request; 
Table 8. Odd ratios based on two multiple logistic regression analyses

\begin{tabular}{lcc}
\hline & \multicolumn{2}{c}{ Preference for GP gender } \\
& Yes $(n=961)$ & Female $(n=223)$ \\
\hline Gender (female = 1) & $1.72^{\mathrm{a}}$ & $21.28^{\mathrm{u}}$ \\
Age & 1.01 & $0.96^{\mathrm{a}}$ \\
Marital status & 0.75 & 0.87 \\
(married = 1) & & \\
Education & 0.94 & 1.14 \\
Prior contact with & $2.85^{\mathrm{a}}$ & $40.51^{\mathrm{a}}$ \\
female GP & & \\
\hline${ }^{\mathrm{a}} P<0.01$. & & \\
\end{tabular}

women. It probably also explains the rather strong same gender preferences for psychiatrists and psychologists, because evaluating the mental health status constitutes a very intimate situation as well.

The reasons for these preferences also have to do with one aspect of humaneness. Persons (regardless of their sex) with a preference for female health professionals find it easier to talk with a female health professional than with a male. In contrast, persons with a preference for male health professionals find it easier to talk with a male health professional than with a female. These findings are in accordance with the study of Fennema et al. (1990). They concluded that patients with a preference for a male viewed humaneness as a male physician trait, while patients preferring a women viewed it as a female physician trait. Our results clearly point to the partnership-building in patientphysician communication as the most important aspect of humaneness.

The communication style of women in general is different to that of men. Hall and Roter (1988), having summarized the results of 41 independent studies of provider-patient communication, reported that female patients received more information and more communication than male patients and physicians directed more positive talk and partnership-building to women. Meeuwesen $e t$ al. (1991) observed from audiotaped consultations that while male GPs were giving more advice and interpretation, female GPs were more attentive and non-directive (giving more subjective and objective behaviour and acknowledgements). Roter et al. (1991) noticed that compared to male physicians, female physicians engaged in more positive talk, partnership-building, question-asking, and information-giving. Bensing et al. (1993) found that male GPs practised a more active communication style (reassuring and information-giving), while female GPs displayed a more passive communication style (listening and counselling). Our results seem to indicate that some women appreciate the passive kind of communication, while some men value more active communication styles. An alternative explanation is given by Waller's assumption that gender is an important component of status, and that female doctors and female patient are much closer in status, thus enabling easier communication (Waller, 1988).

For some health care providers the reason of intimacy and the communication style is not very important (e.g. surgeons and home helps). In the absence of these reasons, people's preferences seem to fall back on the traditional male/female participation in the different health professions $(97 \%$ of the Dutch surgeons are men, $99 \%$ of the home helps are women). In these instances job stereotypes are allied with sex role stereotypes. It is interesting to note, however, the difference in the magnitude of preferences: $15 \%$ gender preferences for surgeons vs $37 \%$ for home helps. Very few people seem to object to a female surgeon, but a lot more seem to object to male home help. This is probably because it is more socially acceptable for a woman to employ a high status profession than it is for a man to employ a low status profession.

Having contacted a female general practitioner showed a strong association with the preference for a female general practitioner. So, prior experience seems to influence gender preferences. Given the correlation design of our study, it is of course not possible to determine whether having had contact is a cause. However, since in the Netherlands all inhabitants are registered on the GPs list, while the majority of GPs are male and work in singlehanded practices the probability of visiting a female GP by chance is not very likely. In general, female patients have to choose a female GP deliberately, and will often have problems in doing so, as even now only $15 \%$ of Dutch GPs are female. Therefore, contacting a female GP must be considered to be an effect of a female preference that existed before the first contact with a female GP took place. The fact that in our study a substantial number of patients who prefer female GPs have been visiting male GPs only is a further argument for this line of reasoning.

Our results show furthermore that there is not only a potential demand for female GPs, but also for gynaecologists. Today more and more women are entering these professions. In the Netherlands $51 \%$ of the GP trainees and $43 \%$ of the gynaecologist trainees are female. But males and females differ clearly in their choice of workplace. Female GPs, for instance, are much more interested in part-time jobs than are male GPs (Brink-Muinen $e t$ al., 1994). This means that although the absolute number of female GPs is rising, the full-time equivalent workload of female GPs is rising much more slowly. And because the majority of GP jobs are full-time jobs, those interested in part-time jobs (women) have more difficulties in finding employment. In order to increase the possibility of patients choosing female GPs and female gynaecologists, policy should be directed towards the education of more women in these professions and the creation of better conditions for part-time jobs. The medical 
profession has made some important steps toward improving women's health services (Clancy and Massion, 1992). A clear understanding of the gender gap will enhance access to health care for all women patients.

Acknowledgements-This research was supported by the Dutch Ministry of Public Health, Welfare and Sports and the Dutch Consumers Union. We would like to thank the referees for their valuable comments.

\section{REFERENCES}

Ackerman-Ross, F. S. and Sochat, N. (1980) Close encounters of the medical kind: attitudes toward male and female physicians. Social Science \& Medicine 14A, 61.

Bem, L. S. (1981) Gender schema theory: a cognitive account of sex typing. Psychological Review 88, 354.

Bensing, J. M., van den Brink-Muinen, A. and de Bakker, D. H. (1993) Gender differences in practice style: a Dutch study of general practitioners. Medical Care 31, 219.

Blake, R. L. Jr (1990) Gender concordance between family practice residents and their patients in an ambulatorycare setting. Academic Medicine 65, 702.

Brink-Muinen, A., de Bakker, D. H. and van den Bensing, J. M. (1994) Consultations for women's health problems: factors influencing women's choice of sex of practitioner. British Journal of General Practice 44, 205.

Challacombe, C. B. (1983) Do women patients need women doctors?. Practitioner 227, 848.

Clancy, C. M, and Massion, C. T. (1992) American women's health care: a patchwork quilt with gaps. Journal of the American Medical Association 268, 1918.

Cook, M. and Ronalds, C. (1985) Women doctors in urban general: the doctors. British Medical Journal 290, 755.

Cook, M. and Ronalds, C. (1985) Women doctors in urban general: the patients. British Medical Journal 290, 753.

Dillner, L. (1993) Why are there not more women consultants: there could be-if all regions did as well as the best. British Medical Journal 307, 949.

Fennema, K., Meyer, D. L. and Owen, N. (1990) Sex of physician: patients' preferences and stereotypes. Journal of Family Practice 30, 441.

Graffy, J. (1990) Patient choice in a practice with men and women general practitioners. British Journal of General Practice 40, 13.

Gray, J. (1982) The effect of the doctor's sex on the doctor-patient relationship. Journal of the Royal College of General Practitioners 32, 167.
Haar, E., Halitsky, V. and Stricker, G. (1975) Factors related to the preference for a female gynecologist. Medical Care 13, 782.

Hall, J. and Roter, D. L. (1988) Meta-analysis of correlates of provider behavior in medical encounters. Medical Care 26, 651.

Hayden, J. (1991) Women in general practice: time to equalise the opportunities. British Medical Journal 303, 733.

Heaton, D. O. and Marquez, J. T. (1990) Patient preferences for physician gender in the male genital exam. Family Practice Research Journal 10, 105.

Hopkins, E. J., Pye, A. M., Solomon, M. and Solomon, S. (1967) A study of patient choice of doctor in an urban area. Journal of the Royal College of General Practitioners 66, 282.

Kelly, J. M. (1980) Sex preference in patient selection of a family physician. Journal of Family Practice 11, 427.

Kitzinger, J. (1990) The internal examination. Practitioner 234, 698.

McPherson, A. and Small, J. (1980) Women general practitioners in Oxfordshire. Journal of the Royal College of General Practitioners 30, 108.

Meeuwesen, L., Schaap, C. and van der Staak, C. (1991) Verbal analysis of doctor-patient communication. Social Science \& Medicine 32, 1143.

Nichols, S. (1987) Women's preferences for sex of doctor: a postal survey. Journal of the Royal College of General Practitioners 37, 540.

Odegaard, C. (1986) Dear Doctor: A Personal Letter to a Physician. Henri Kaiser Foundation, Menlo Park, CA.

Preston-Whyte, M. E., Frasier, R. C. and Beckett, J. L. (1983) Effect of a principal's gender on consultation patterns. Journal of the Royal College of General Practitioners 33, 654.

Roter, D., Lipkin, M. Jr and Korsgaard, A. (1991) Sex differences in patients' and physicians' communication during primary care medical visits. Medical Care 29, 1083.

Shapiro, E. T. (1979) Does the sex of the physician matter?. Behavourial Medicine 6, 17.

Waller, K. (1988) Women doctors for women patients?. British Journal of Medical Psychology 61, 125.

Weisman, C. S. and Teitelbaum, M. A. (1985) Physician gender and the physician-patient relationship: recent evidence and relevant questions. Social Science \& Medicine 20, 1119.

Weyrauch, K. F., Boiko, P. E. and Alvin, B. (1990) Patient sex role and preference for a male or female physician. Journal of Family Practice 30, 559.

White, K. L. (1988) The Task of Medicine. Dialogue at Wickenburg. Henri Kaiser Foundation, Menlo Park, CA. 